\title{
Biologia reprodutiva dos bagres marinhos Genidens genidens (Valenciennes) e Cathorops spixii (Agassiz) (Siluriformes, Ariidae), na Baía de Sepetiba, Rio de Janeiro, Brasil
}

\author{
Iracema David Gomes 1 \\ Francisco Gerson Araújo 1 \\ Marcia Cristina Costa de Azevêdo 1 \\ André Luiz Machado Pessanha 1
}

\begin{abstract}
Reproductive biology of the marine catfish Genidens genidens Valenciennes and Cathorops spixii Agassiz (Siluriformes, Ariidae) in the Sepetiba Bay, Rio de Janeiro, Brazil. The reproductive cycle of the marine catfishes Genidens genidens Valenciennes, 1833 and Cathorops spixii Agassiz, 1839 in the Sepetiba Bay, was assessed by an annual period of sampling from October 1993 to September 1994. The fishes were caught by standardized otter trawl and environmental parameters of temperature, salinity and transparency of water were recorded at each sampling. Five gonadal phases were described, based in macroscopic observations. Changes in the gonadosomatic index (GSI) and in the percentual of stages of gonadal development showed that $G$. genidens spawns in Summer/early Autumn, coinciding with low salinity and high temperature and transparency. Cathorops spixii spawns in late Spring/early Summer, coinciding with rising temperature and transparency and low salinity. Total spawning are shown for both species, as indicated by length-frequency of oocytes per stages of maturation with two groups synchronic development of oocytes. Fecundity is low (10-23 oocytes, for G. genidens and 24-30 for C. spixii), when compared with other teleosteans, and was not strongly correlated to the total length $(G$. genidens, $\mathrm{r}=0.65, C$. spixii, $\mathrm{r}=0.76)$. Strategy-k is developed by both species as indicated by high brood and enbrions protection and high body length.

KEY WORDS. Siluriformes, Ariidae, reproduction, Marine Catfish, Sepetiba Bay
\end{abstract}

Os bagres marinhos pertencentes à família Ariidae ocorrem em zonas litorâneas sendo geralmente mais abundantes em águas costeiras pouco profundas, em fundo lodoso ou arenoso (ARAÚJo 1988; ANDREATA et al. 1989). São considerados como recursos de grande importância econômica na pesca artesanal, principalmente na região sul (REIS 1986a). Na época da desova, procuram a desembocadura dos rios e regiões lagunares realizando incubação oral com machos e raramente as fêmeas, carregando ovos e formas iniciais da prole até completarem o desenvolvimento embrionário (YAÑEZ-ARANCIBIA \& SANCHEZ-GIL 1988; REIS 1986b).

A biologia reprodutiva deste grupo de peixes é pouco estudada na costa do Brasil e isto faz com que especial interesse seja direcionado para as espécies Genidens genidens e Cathorops spixii devido sua grande distribuição em estuários

1) Laboratório de Ecologia de Peixes, Posto de Aqüicultura, Universidade Federal Rural do Rio de Janeiro. Antiga Rodovia Rio-São Paulo, Km 47, 23851-970 Seropédica, Rio de Janeiro, Brasil. E-mail: gerson@ufrrj.br 
e lagoas costeiras do sudeste do Brasil (Mishima \& TANJI 1981); dos poucos trabalhos sobre o assunto citam-se os de MisHIMA \& TANJI (1983) e REIS (1986b) para o estuário da Lagoa dos Patos, Rio Grande do Sul; BARBIERI et al. (1992) para a Lagoa de Jacarepaguá, Rio de Janeiro e CHAves (1994) para Baía de Guaratuba, Paraná.

MisHIMA \& TANJ (1983) descreveram a biologia reprodutiva de algumas espécies de bagres na região estuarino-lagunar no sudeste do Brasil, mas em suas amostras a quantidade de $G$. genidens foi pequena, impossibilitando estudos mais detalhados sobre o período da desova e a fecundidade. BARBIERI et al. (1992) determinaram o comprimento de primeira maturação sexual de G. genidens e a fecundidade; CHAVES (1994) descreveu aspectos da dinâmica de incubação de ovos e larvas de G. genidens; REIS (1986b) estudou a reprodução de Netuma barba Lacépède, 1803. O objetivo deste estudo, é descrever aspectos da biologia reprodutiva de G. genidens e C. spixii na Baía de Sepetiba, com ênfase na determinação da época e tipo de desova, desenvolvimento ovocitário e fecundidade.

\section{MATERIAL E MÉTODOS}

A Baía de Sepetiba localiza-se no Estado do Rio de Janeiro entre as latitudes $22^{\circ} 54^{\prime}$ e $23^{\circ} 04^{\prime} \mathrm{S}$ e as longitudes $43^{\circ} 34^{\prime} \mathrm{e} 44^{\circ} 10^{\prime} \mathrm{W}$ (DHN 1984). Apresenta forma alongada, limitando-se ao Norte e a Leste pelo continente, ao Sul pela Restinga de Marambaia e a Oeste pela Baía de Ilha Grande. Considerada como um dos mais importantes ecossistemas marinhos do Estado do Rio de Janeiro, perfaz uma área de aproximadamente $305 \mathrm{Km}^{2}$. Seu maior comprimento é de $43 \mathrm{~km}$ no sentido leste-oeste e sua maior largura é de $17 \mathrm{~km}$ no sentido norte-sul, sendo seu perímetro de aproximadamente $123 \mathrm{~km}$. A bacia hidrográfica apresenta área aproximada de $1800 \mathrm{Km}^{2}$ (Coelho \& CARValho 1973). O substrato da Baía é principalmente lodoso, com formações de silte, argila, e com poucas áreas de areia e cascalho na zona externa.

Os espécimes de $G$. genidens e C. spixii foram coletados e identificados (FIGUEIREDO \& MENEZES 1978) em amostragens bimestrais de arrastos de fundo entre outubro de 1993 a setembro, de 1994. Os arrastos de fundo, de duração padronizada de meia hora, foram realizados por embarcação do tipo arrasteiro de $12 \mathrm{~m}$ de comprimento, que realiza pesca comercial na Baía. Em cada amostragem foram medidos os parâmetros ambientais de transparência, salinidade e temperatura, além de ter sido feita a biometria, com a posterior conservação de espécimens em formol a $10 \%$.

Os peixes foram pesados (em gramas), medidos (em milímetros) e dissecados em laboratório; das gônadas analisadas foram observados a coloração, o peso (g) e o comprimento $(\mathrm{mm})$. A identificação dos estádios de maturação gonadal, feita através do uso microscópio estereoscópio, foi adaptada através de cinco fases baseadas na escala proposta de VAZZOLER (1982): imaturo, em maturação inicial, em maturação final, maduro e desovado (fêmeas) /esvaziado (machos).

O padrão de desenvolvimento ovariano foi determinado através da distribuição do diâmetro dos ovócitos por diferentes estádios de maturação. Foram separados 10 ovários pôr fase de maturação, e de cada ovário foram medidos cerca de 30 ovócitos aleatoriamente selecionados, com as medições sendo realizadas através da 
objetiva com escala micrométrica, com precisão $0,1 \mathrm{~mm}$. Os ovócitos vitelogênicos foram medidos com paquímetro com precisão de 1 milímetro.

O Índice Gônado Somático (IGS) foi calculado através do percentual do peso das gônadas em relação ao peso total do peixe para cada sexo separadamente de todos os indivíduos coletados pela seguinte equação: IGS = Wg / Wt .100.

Os ovócitos, para melhor dissociação, foram conservados em solução de Gilson, o que facilitou na determinação da fecundidade a qual foi determinada através da contagem do número de ovócitos vitelogênicos em fêmeas maduras. Foi determinada a relação entre a fecundidade e o comprimento total utilizando o método dos mínimos quadrados.

\section{RESULTADOS}

\section{Estrutura da população}

\section{Genidens genidens}

A estrutura de tamanho da população compreendeu indivíduos com comprimento total (CT) entre 115 e $415 \mathrm{~mm}$, com fêmeas predominando nos grupos de menor tamanho $(\mathrm{CT}<175 \mathrm{~mm})$ e machos, em sua maioria, em grupos de maior tamanho (CT>200 mm).

\section{Cathorops spixii}

Foram amostrados peixes apresentando comprimento total (CT) entre $91 \mathrm{e}$ $325 \mathrm{~mm}$, com fêmeas predominando nos grupos de tamanho de 180 a $210 \mathrm{~mm}$ CT, e os machos, nos grupos de tamanho 180 a $190 \mathrm{~mm} \mathrm{CT}$.

\section{Estádios de maturação sexual}

Foi examinado para $G$ genidens um total de 208 indivíduos, sendo 95 fêmeas, 44 machos, e 69 indivíduos jovens dos quais não foi possível fazer a sexagem; para C. spixii foram examinados 100 indivíduos sendo 58 fêmeas, 25 machos e 17 jovens cujo sexo não foi identificado.

O desenvolvimento gonadal foi descrito de acordo com caracteres macroscópicos das gônadas tendo sido considerado o peso, comprimento, forma, coloração e ocupação relativa da cavidade abdominal (Tabs I, II). Para as fêmeas das duas espécies foram estabelecidos cinco estádios de desenvolvimento com suas variações também tomando por base a morfologia das gônadas e o diâmetro dos ovócitos.

\section{Desenvolvimento dos ovócitos e tipo de desova}

\section{Genidens genidens}

O diâmetro dos ovócitos variou de $<0,1 \mathrm{~mm}$ a $20 \mathrm{~mm}$. O estádio maduro apresentou dois grupos de tamanho: o primeiro grupo de ovócitos não desenvolvidos, cujo diâmetro variou entre $3,5 \mathrm{~mm}$ e $11 \mathrm{~mm}$ e o segundo grupo de ovócitos vitelogênicos com diâmetro variando de $14 \mathrm{~mm}$ a $20 \mathrm{~mm}$. O primeiro grupo de ovócitos não voltou a aparecer no estádio desovado, o que implica que os mesmos tenham sido reabsorvidos após a reprodução, ou tenham sido eliminados juntamente com os ovócitos vitelogênicos. Para as outras fases, o diâmetro não ultrapassou $5 \mathrm{~mm}$ (Fig.1). 
Tabela I. Características dos estádios macroscópicos dos ovários de fêmeas de G. genidens e C. spixii.

\begin{tabular}{|c|c|}
\hline Estádios de maturaçăo & Caracteristicas \\
\hline Imaturo & $\begin{array}{l}\text { Ovários translúcidos, menor que } 0,03 \mathrm{~g} \text {; de coloração esbranquiçada. Ovócitos muito pequenos, } \\
\text { em desenvolvimento, de forma assimétrica observados com o auxilio do microscópio } \\
\text { estereoscópio em amplificação minima de } 40 \mathrm{x} \text {. Filiformes e alongados em G. genidens e } \\
\text { alongados com tendéncia à forma lobulada em C. spixii. }\end{array}$ \\
\hline Maturação Inicial & $\begin{array}{l}\text { Apresentam ovócitos já visiveis a olho nu, muito pequenos e aderidos à parede ovariana e } \\
\text { coloração cremosa. Genidens genidens exibiu ovários com pequeno alargamento e peso de } \\
\text { aproximadamente } 0,03 \mathrm{~g} \text {, enquanto } C \text {. spixii apresentou forma semelhante à fase anterior e peso } \\
\text { entre } 0,03 \mathrm{~g} \text { e } 0,2 \mathrm{~g} \text {. }\end{array}$ \\
\hline Maturação Final & $\begin{array}{l}\text { Apresentam um maior alargamento que na fase anterior com coloração amarelada. Tendẻncia à } \\
\text { forma lobulada com variação de peso de } 0,04 \mathrm{~g} \text { a } 1 \mathrm{~g} \text { para } \mathrm{G} \text {. genidens e forma lobulada para } C \text {. } \\
\text { spixii com variaçăo no peso de } 0,2 \mathrm{~g} \text { a } 1,6 \mathrm{~g} \text {. }\end{array}$ \\
\hline Maduro & $\begin{array}{l}\text { Lobulares, volumosos, ocupando cerca de } 1 / 3 \text { da cavidade abdominal. Ovócitos de cor alaranjada, } \\
\text { heterogêneos de tamanhos pequeno e médio. Parede ovariana fina. O peso máximo encontrado } \\
\text { para G. genidens foi de } 40,8 \mathrm{~g} \text {, enquanto para C. spixii foi de } 6,62 \mathrm{~g} \text {. }\end{array}$ \\
\hline Desovado & $\begin{array}{l}\text { Flácidos, menores que os da fase anterior e apresentam ovócitos heterogêneos podendo ser } \\
\text { residuais e em degeneração. A variaçăo do peso encontrado para } G \text {. genidens foi de } 0,3 \text { a } 2,1 \mathrm{~g} \\
\text { e para } C \text {. spixii foi de } 0,1 \text { a } 1,7 \mathrm{~g} \text {. }\end{array}$ \\
\hline
\end{tabular}

Tabela II. Características dos estádios macroscópicos dos testículos de machos de G.genidens e C. spixii.

\begin{tabular}{lc}
\hline Estádios de maturação & Características \\
\hline Imaturo & Filiformes, pequenos, de coloração branca, com comprimento menor que $2,0 \mathrm{~cm}$ e peso $<0,01 \mathrm{~g}$. \\
Maturação inicial & Apresentam-se mais largos que os da fase anterior, comprimento em torno de $4,5 \mathrm{~cm}$ para $\mathrm{G}$. \\
& genidens e $3 \mathrm{~cm}$ para C. spixii, o peso encontrado năo ultrapassou de $0,04 \mathrm{~g}$ em ambas espécies. \\
Maturação final & Diferenciam-se dos testiculos da fase anterior principalmente pelo peso $(>0,05 \mathrm{~g})$. \\
Maduro & Largos, compridos, de coloraçăo branca opaca, ocupam aproximadamente $2 / 3$ da cavidade corporal \\
& e apenas $G$. genidens apresentam margem levemente sinuosa. O maior peso encontrado foi de \\
& $0,25 \mathrm{~g}$ para G. genidens e $0,6 \mathrm{~g}$ para C. spixii. \\
Esvaziado & Coloraçăo branca e quando manipulados se apresentam flácidos e com peso năo ultrapassando de \\
& $0,01 \mathrm{~g}$.
\end{tabular}

\section{Cathorops spixii}

$\mathrm{O}$ diâmetro dos ovócitos variou de $<0,1 \mathrm{~mm}$ a $12 \mathrm{~mm}$, e foi observado em todas as fases o diâmetro $<0,1 \mathrm{~mm}$. O estádio maduro apresentou dois grupos de tamanho: o primeiro grupo de ovócitos não desenvolvidos, cujo diâmetro variou entre $<0,1 \mathrm{~mm}$ a $4 \mathrm{~mm}$ e $o$ segundo grupo de ovócitos vitelogênicos com diâmetro variando de $6 \mathrm{~mm}$ a $12 \mathrm{~mm}$. Os ovócitos de maior diâmetro, assim como em $G$. genidens, não reapareceram no estádio desovado (Fig. 2).

\section{Índice gônado somático e período de reprodução}

\section{Genidens genidens}

Os valores médios do IGS dos machos, apresentaram aumento considerável em fevereiro/março e atingiram o pico em abril/maio, enquanto para fêmeas, atingiram pico em dezembro/janeiro (Fig. 3). Os menores valores de machos e fêmeas ocorreram entre junho e setembro. Este padrão temporal sugere que as fêmeas a partir de dezembro se encontram prontas para a reprodução, com a maioria dos machos maduros só ocorrendo nos meses subsequentes, principalmente entre fevereiro e maio.

$\mathrm{Na}$ fase madura, a maior freqüência de machos ocorreu em fevereiro/março e de fêmeas em dezembro/janeiro, coincidindo com as informações de IGS e sugere 
ser uma reprodução durante o verão e início do outono (Fig. 4). O período reprodutivo coincidiu com elevadas temperatura e transparência e baixas salinidade da água (Fig. 5).

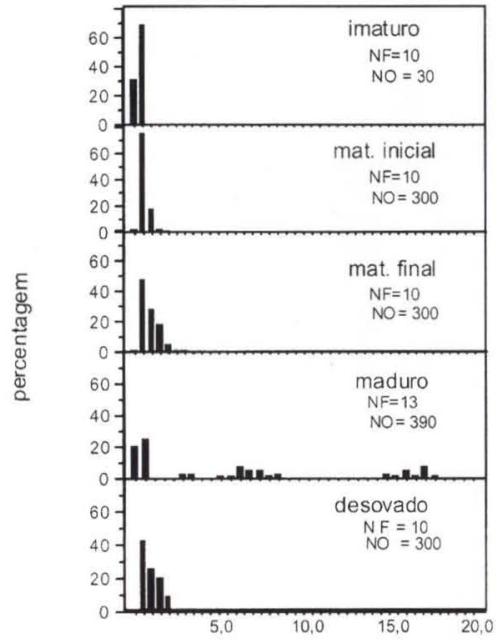

1

diâmetro doovócito $(\mathrm{mm})$

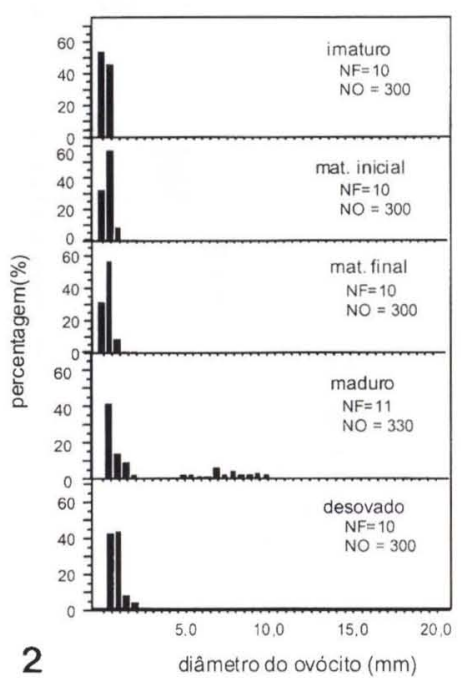

Figs 1-2. Distribuição de freqüências de diâmetro de ovócitos por estádios de maturação de fêmeas, entre outubro-93 e setembro-94, na Baía de Sepetiba, Rio de Janeiro. (1) G. genidens; (2) C. spixii. (NO) Número de ovócitos, (NF) número de fêmeas.

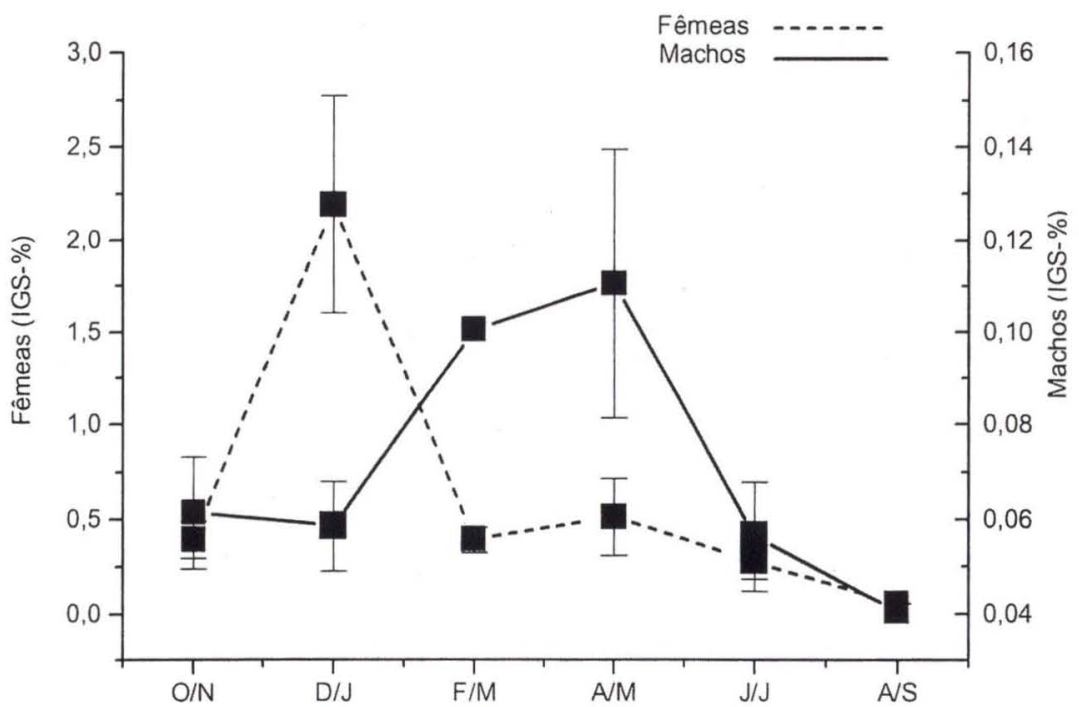

Fig. 3. Variação bimestral do Indice Gonado Somático (IGS) em machos e fêmeas de $G$. genidens, entre outubro-93 e setembro-94 na Baía de Sepetiba, Rio de Janeiro. 

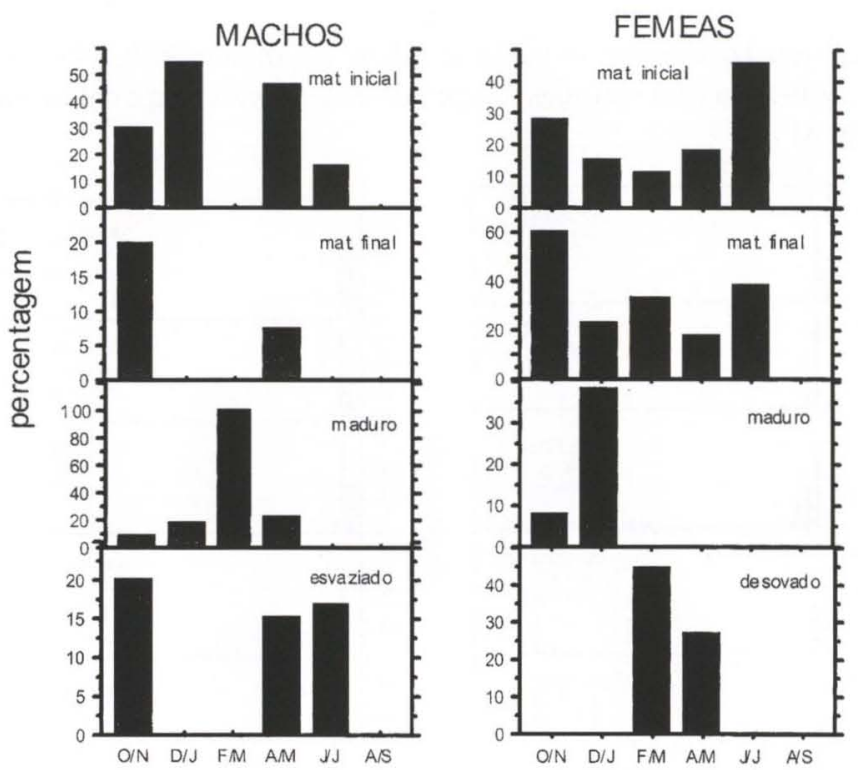

Fig. 4. Variação bimestral de freqüências de estádios de maturação em machos e fêmeas de G. genidens, entre outubro-93 e setembro-94, na Baía de Sepetiba, Rio de Janeiro.

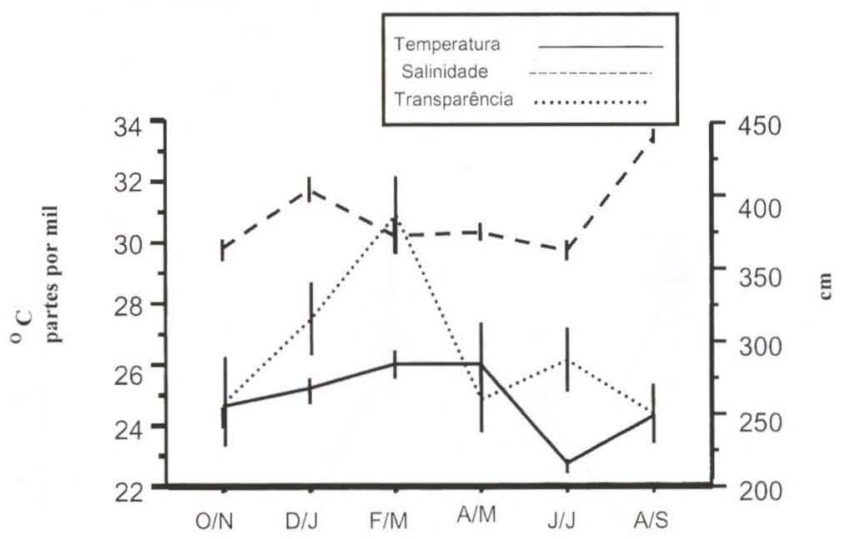

Fig. 5. Variação bimestral de temperatura, salinidade e transparência da água, entre outubro93 e setembro-94, na Baía de Sepetiba, Rio de Janeiro.

\section{Cathorops spixii}

Os valores médios de IGS de machos, apresentaram aumento em outubro/novembro com pico em dezembro/janeiro e as fêmeas apresentaram pico em outubro/novembro. Os menores valores de machos e fêmeas ocorreram entre fevereiro e setembro (Fig. 6). 


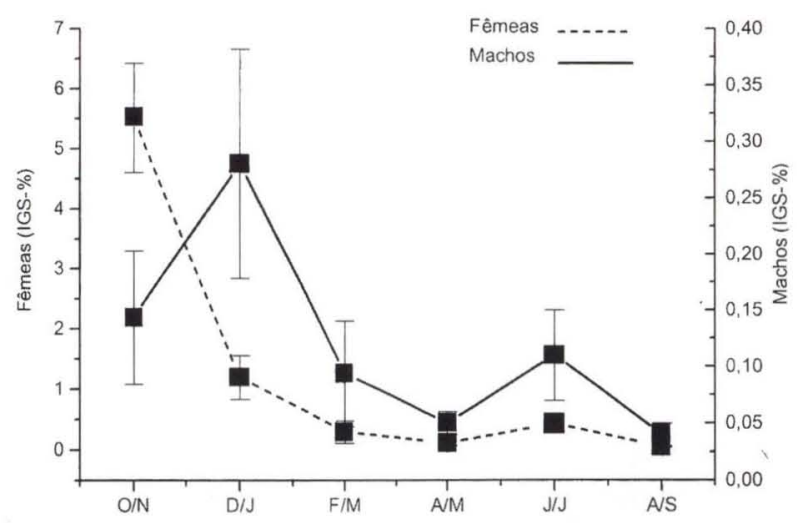

Fig. 6. Variação bimestral do Indice Gonado Somático (IGS) em machos e fêmeas de C. spixii, entre outubro-93 e setembro-94. na Baía de Sepetiba, Rio de Janeiro.

Nos meses de outubro/novembro, machos e fêmeas em estádio maduro foram mais freqüentes, enquanto machos no estádio esvaziado e fêmeas no estádio desovado ocorreram em fevereiro/março (Fig. 7). Esses resultados, principalmente de fêmeas coincidem com os valores de IGS sugerindo uma reprodução entre a primavera e início do verão, portanto, um pouco anterior a de $G$. genidens. No período reprodutivo, os valores de temperatura e transparência encontram-se em elevação e a salinidade é baixa (Fig. 5).

\section{Fecundidade}

A fecundidade foi avaliada através da contagem do número de ovócitos vitelogênicos em 13 fêmeas examinadas de $G$. genidens com número mínimo de ovócitos por fêmeas de 10 e o número máximo foi de 24 , com média de 14,8 . Em 11 fêmeas de C. spixii, o número de ovócitos por fêmea madura observado foi superior ao de G. genidens: mínimo 17, máximo 42, média de 25.

A relação entre a fecundidade e o comprimento total foi considerada a partir da expressão: $y=a+b x$, tendo-se obtido as seguintes equações (Fig. 8) :

Fecundidade $=-2,76+0,077$. CT e $r=0,65-G$. genidens

Fecundidade $=-50,1+0,38$. CT e $\mathrm{r}=0,76-C$. spixii

Cathorops spixii apresentou maior correlação linear (r) entre a fecundidade e o comprimento total, quando comparada com $G$. genidens embora para ambos as espécies não tenha sido detectada correlação altamente significativa. Os maiores coeficientes de regressão para C. spixii indicam que fêmeas de maior tamanho apresentam maior número de ovócitos, quando comparados com G. genidens, cujo aumento de tamanho não parecer ser tão associado ao aumento da fecundidade.

\section{DISCUSSÃO}

Genidens genidens e C. spixii apresentam desova total com desenvolvimento ovocitário sincrônico em dois grupos para as duas espécies. Este desenvolvimento é definido por evidenciar dois lotes de ovócitos dentro dos ovários (especialmente os maduros): 1) o dos ovócitos de estoque de reserva e 2) o dos ovócitos vitelogênicos que irão maturar e serão eliminados no período da desova (VAZZOLER 1996). 


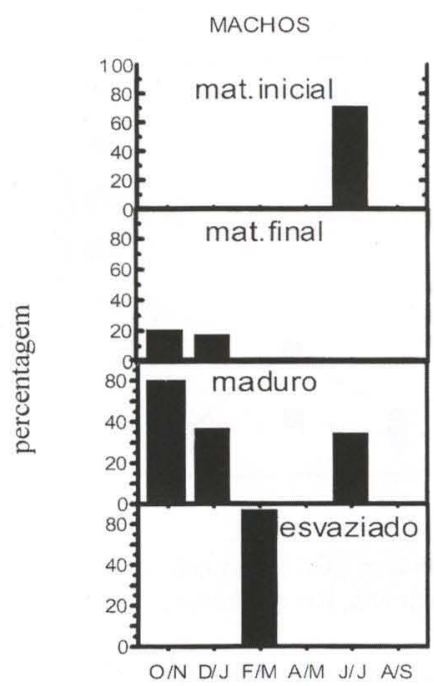

FÊMEAS

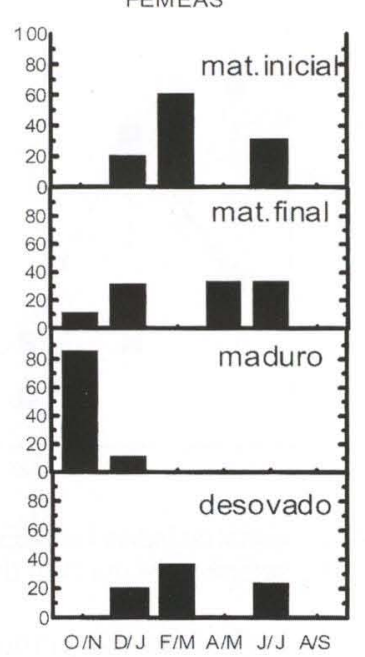

Fig. 7. Variação bimestral de freqüências estádios de maturação em machos e fêmeas de $C$. spixii, entre outubro-93 e setembro-94, na Baía de Sepetiba, Rio de Janeiro.

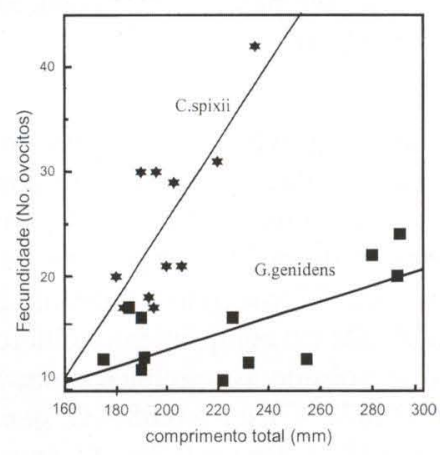

Fig. 8. Diagrama de dispersão entre a fecundidade e o comprimento total de G. Genidens e C. spixii, entre outubro-93 e setembro-94, na Baía de Sepetiba, Rio de Janeiro.

Este padrão foi denominado por MARZA in YAMAMOTO (1970) como "synchronisme par groupes", caracterizado por apresentar ovários com nítida diferença entre normais e atrofiados. Este tipo de distribuição dos ovócitos enquadra-se também na classificação de VAZZOLER (1996) como desenvolvimento sincrônico em dois grupos, e indica liberação de um único lote de ovócitos maduros durante a reprodução. MISHIMA \& TANJI (1983) encontraram este mesmo tipo de desova em bagres com as espécies apresentando uma única liberação anual de ovócitos em um curto espaço de tempo. Diferenças no padrão de tamanho dos ovócitos foram observados nas duas espécies; MISHIMA \& TANJI (1983) estabeleceram para G. genidens o diâmetro médio de ovócitos vitelogênicos de 14,9 mm (máximo de 15,5 mm - 
mínimo de $14,3 \mathrm{~mm}$ ); sendo, portanto inferior ao encontrado neste trabalho para a Baía de Sepetiba. Os mesmos autores encontraram para C. spixii diâmetro médio de $9,1 \mathrm{~mm}$ (mín.=8 mm - máx.=10 mm), coincidindo com os de $C$. spixii neste estudo. BARBIERI et al. (1992) distinguiram em G. genidens três grupos de tamanho de ovócitos, sendo o primeiro grupo composto por ovócitos não desenvolvidos (1-3 $\mathrm{mm}$ ); um segundo grupo intermediário $(4-7 \mathrm{~mm})$ e o terceiro por ovócitos vitelogênicos $(8-13 \mathrm{~mm}$ ). REIS (1986b) trabalhando Netuma barba (outra espécie de Ariidae) de maior tamanho, também observou três grupos, sendo o primeiro não considerado; o segundo entre 2-4 mm e o terceiro entre 12,3-19,5 mm.

Machos de G. genidens e C. spixii atingiram pico nos valores de IGS no período posterior ao das fêmeas. Isto pode estar associado a um período de jejum dos machos que encontram-se realizando incubação oral após a desova. O período reprodutivo de C. spixii coincidiu com o encontrado por MISHIMA \& TANJ (1983), enquanto para $G$. genidens, foi o mesmo de BARBIERI et al. (1992) para mesma espécie. Esta separação temporal, com C. spixii desovando um pouco antes de $G$. genidens, pode ser uma estratégia reprodutiva das duas espécies para evitar competição.

Os valores elevados de IGS em fêmeas de G. genidens e C. spixii coincidem com aumentos da temperatura, transparência e com baixa salinidade; BARBIERI et al. (1992) encontraram maiores IGS de G. genidens em elevadas temperaturas, porém em baixas salinidades. As elevações de temperaturas, associadas às baixas salinidades de entradas de estuários constituem locais prediletos de reprodução destas espécies (REIS 1986b; ARAÚJO 1988; ChAVES 1994; ARAÚJO 1998).

De acordo com VAzzoler (1996), o tamanho dos ovócitos está relacionado ao comportamento reprodutivo e espécies de ovócitos grandes como os bagres marinhos, são migradoras, de fecundação externa com cuidado à prole. A baixa fecundidade observada, comum em bagres marinhos, está associada ao grande tamanho dos ovócitos vitelogênicos. Isto indica um grande esforço reprodutivo das fêmeas caracterizando uma tendência à estratégia-K onde maior parte da energia é direcionada para o processo de desova associado a cuidados parentais bem desenvolvidos. Não foram observados bagres realizando incubação oral, embora tenham sido encontradas evidências do período reprodutivo, com indivíduos apresentando a região da mandíbula bastante dilatada e o corpo afilado (magro). Machos de bagres marinhos foram encontrados realizando incubação oral com ovos e juvenis com o saco vitelínico em absorção por vários autores (GUNTER 1947; ARAÚJo 1988; REIS 1986b; BARBIERI et al. 1992). Portanto, estes peixes são classificados conforme VAZZOLER (1996) como "carregadores externos" por carregarem embriões e/ou jovens na boca, transferindo-os de um local para outro. Considera-se, portanto, a Baía de Sepetiba como área favorável ao processo reprodutivo, por apresentarem condições ambientais propícias à fecundação e desenvolvimento da prole.

\section{REFERÊNCIAS BIBLIOGRÁFICAS}

ANdreata, J.V.; L.R. BARBIERI; A.S.B. Sebilia; M.H.C. DA Silva \& R.P. Dos SANTOS. 1989. A list of Marapendi Lagoon fishes, Rio de Janeiro, Brazil. Atlântica, Rio Grande, 11: 5-17. 
ARAÚJO, F.G. 1988. Distribuição, abundância relativa e movimentos sazonais de bagres marinhos (Siluriformes, Ariidae) no estuário da Lagoa dos Patos (RS), Brasil. Revta bras. Zool. 5 (4): 509-543.

1998. Maturação e desova do bagre marinho Genidens genidens Valenciennes, 1833 (Siluriformes, Ariidae) na Baía de Sepetiba, RJ. Acta Biol. Leopoldensia 20 (1): 109-122.

BARBIERI, L.R.; R.P.J. DOS SANTOS \& J.V. ANDREATA. 1992. Reproductive biology of the marine catfish, Genidens genidens (Siluriformes, Ariidae), in the Jacarepaguá lagoon system, Rio de Janeiro, Brazil. Environ. Biol. Fishes 35: 23-35.

ChAves, P.T.C. 1994. A incubação de ovos e larvas em Genidens genidens (Valenciennes) (Siluriformes, Ariidae) da Baía de Guaratuba, Paraná, Brasil. Revta bras. Zool. 11 (4): 641-648.

Coelho, V.M.B. \& R.R. CARvalho. 1973. Levantamento sanitário da Baía de Sepetiba e suas possibilidades como corpo receptor de cargas poluidoras da região. Publ. Avuls. FEEMA, 87p.

DHN. 1984. Baía de Sepetiba. Carta náutica. Rio de Janeiro, Diretoria de Hidrografia e Navegação, N. 1621.

FigueIREDO, J.L. \& N.A. MENEZES. 1978. Manual de peixes marinhos do sudeste do Brasil. II. Teleostei (1). São Paulo, Museu de Zoologia da Universidade de São Paulo, 110p.

GUNTER, G. 1947. Observations on breeding of the marine catfish, Galeichthys felis (Linneaus). Copeia 1947: 217-223.

MishimA, M. \& S. TANJI. 1981. Distribuição geográfica dos bagres marinhos (Osteichthyes, Ariidae) no complexo lagunar de Cananéia $\left(25^{\circ} \mathrm{S}, 48^{\circ} \mathrm{W}\right)$. Boletim Instituo de Pesca 9: 131-40.

- 1983. Maturação e desova dos bagres marinhos (Osteichthyes, Ariidae) do complexo lagunar de Cananéia $\left(25^{\circ} \mathrm{S}, 48^{\circ} \mathrm{W}\right)$. Bol. Inst. Pesca 10: 129-141.

REIS, E.G. 1986a. A pesca artesanal de bagres marinhos (Silurifornes, Ariidae) no estuário da Lagoa dos Patos (RS), Brasil. Rio Grande, FURG, Documentos técnicos 5, 22p.

- 1986b. Reproduction and feeding habits of the marine catfish Netuma barba (Siluriformes, Ariidae), in the estuary of Lagoa dos Patos, Brasil. Atlântica, Rio Grande, 8: 35-55.

VAZZOLER, A.M.A. DE M. 1982. Manual e métodos para estudos biológicos de populações de peixes. Reprodução e crescimento. Brasília, CNPq/Programa Nacional de Zoologia, 108p.

— 1996. Biologia da reprodução de peixes teleósteos: teoria e prática. Maringá, Editora Universidade Estadual de Maringá e Sociedade Brasileira de Ictiologia, $169 \mathrm{p}$.

YAMAMOTO, K. 1970. Reproduction, p. 233-371. In. N. KAWAMOTO (Ed.). Gyorui seiri (Fish physiology). Tokyo, Koseisha-Koseikaku, 482p.

YaÑEZ-ArAncibia, A. \& P. SÀnChEZ-Gil. 1988. Ecologia de los recursos demersales marinos. México, AGT Editor S.A., 228p.

Recebido em 27.V.1998; aceito em 19.XI.1999. 